Revista

Ibero-Americana

de Estratégıa

\title{
STAKEHOLDERS: ESTRATÉGIA ORGANIZACIONAL E RELACIONAMENTO. ESTUDO DE CASOS MÚLTIPLOS DO SETOR HOTELEIRO
}

STAKEHOLDERS: ORGANIZATIONAL STRATEGY AND RELATIONSHIP. A MULTIPLE CASE STUDY IN THE HOTEL SECTOR

STAKEHOLDERS: ESTRATEGIA ORGANIZACIONAL Y RELACIÓN ESTUDIO DE CASOS MÚLTIPLES DEL SECTOR HOTELERO

\section{Rosemeire Rodrigues Junqueira}

Mestre em Hospitalidade pela Universidade Anhembi Morumbi - UAM

Professora de Turismo na Organização não Governamental Fênix

E-mail: rosejunq@gmail.com (Brasil)

\section{Elizabeth Kyoko Wada}

Doutora em Ciências da Comunicação pela Universidade de São Paulo - USP

Professora e coordenadora do Programa de Mestrado em Hospitalidade da Universidade Anhembi Morumbi - UAM

E-mail: ewada@uol.com.br (Brasil) 


\section{STAKEHOLDERS: ESTRATÉGIA ORGANIZACIONAL E RELACIONAMENTO. ESTUDO DE CASOS MÚLTIPLOS DO SETOR HOTELEIRO}

\section{RESUMO}

A pesquisa sobre a gestão organizacional voltada para o relacionamento com os stakeholders referese à importância da construção do envolvimento de vários grupos no desenvolvimento dos negócios, de forma a criar e distribuir valor. Para uma melhor visualização e entendimento da estratégia voltada para a gestão com os stakeholders e seu aproveitamento nas redes hoteleiras, a abordagem qualitativa com a metodologia voltada para o estudo de casos múltiplos foi a mais adequada para a investigação empírica. Para essa investigação, foram selecionadas três redes de hotéis por reunirem características que viabilizariam a análise comparativa do estudo, de acordo com o método sugerido por Yin (2010), em que foram utilizadas para coleta de dados, três fontes de evidências: entrevistas, observações diretas e documentação. Por intermédio desta pesquisa, foi possível identificar que, por meio de uma gestão voltada para a transparência, para a ética, para os valores e, principalmente, para o respeito mútuo, a estratégia pode ser mais colaborativa e resultar no aumento da sustentabilidade das organizações.

Palvras-chave: Estratégia; Hotelaria; Relacionamento; Stakeholders.

\section{STAKEHOLDERS: ORGANIZATIONAL STRATEGY AND RELATIONSHIP.}

\section{A MULTIPLE CASE STUDY IN THE HOTEL SECTOR}

\section{ABSTRACT}

Research into organizational management that focuses on relationships with stakeholders refers to the importance of the commitment of the various groups in the business development prioritizing the creation and distribution of values. For a better view and understanding of strategy-oriented management with stakeholders and the usage of this strategy in hotel chains, a qualitative approach to the methodology, focused on multiple case studies, was the most suitable for empirical investigation. Three hotel chains were selected, with features that allowed a comparative analysis of the study according to the method suggested by Yin (2010), with three sources of evidence: interviews, direct observations and documentation. Through this research, it was found that, through transparency, ethics, values and especially mutual respect clearly shown by the management, a strategy can be more collaborative and result in increasing the sustainability of organizations.

Keywords: Stakeholders; Strategy; Relationship; Hotel Management.

Revista Ibero-Americana de Estratégia - RIAE, São Paulo, v. 10, n. 3, p. 94-125, set./dez. 2011. 


\section{STAKEHOLDERS: ESTRATEGIA ORGANIZACIONAL Y RELACIÓN \\ ESTUDIO DE CASOS MÚLTIPLES DEL SECTOR HOTELERO}

\section{RESUMEN}

La investigación sobre la gestión organizacional con énfasis en la relación con los stakeholders se refiere a la importancia de la construcción de la participación de varios grupos en el desarrollo de los negocios con el objetivo de crear y distribuir valor. Para una mejor visualización y entendimiento de la estrategia centrada para la gestión con los stakeholders y su aprovechamiento en las redes hoteleras, el enfoque cualitativo con la metodología de estudio de casos múltiples fue la más adecuada para la investigación empírica. Para este estudio fueron seleccionados tres redes de hoteles por reunir características que viabilizarían el análisis comparativo del estudio de acuerdo con el método sugerido por Yin (2010), en el que fueron utilizados para la recolección de los datos, tres fuentes de evidencias: las entrevistas, las observaciones directas y la documentación. A través de esta investigación fue posible identificar que, por medio de una gestión centrada para la transparencia, para la ética, para los valores y principalmente para el respeto mutuo, la estrategia puede ser más colaborativa y resultar en el aumento de la sustentabilidad de las organizaciones.

Palabras-clave: Stakeholders; Estrategia; Relación; Hotel.

Revista Ibero-Americana de Estratégia - RIAE, São Paulo, v. 10, n. 3, p. 94-125, set./dez. 2011. 
Stakeholders: Estratégia Organizacional e Relacionamento. Estudo de Casos Múltiplos do Setor

Hoteleiro

\section{INTRODUÇÃO}

A administração organizacional atravessa um processo de aprendizagem e de renovação do conhecimento na busca de um desempenho mais eficiente, em que, com a economia do conhecimento, as organizações adquirem fortes responsabilidades sociais além de se mostrarem eficientes no desenvolvimento da inovação e da colaboração dos grupos envolvidos no negócio. A integração da sociedade, tanto pela comunicação quanto pela facilidade de deslocamento, muda o comportamento competitivo das organizações direcionando-as para uma concorrência global.

Nesta conjunção, as empresas se tornam mais complexas e necessitam usar, desenvolver e disseminar seu conhecimento pela organização com seus stakeholders, que, por sua vez, têm responsabilidades a serem cumpridas. A definição das estratégias, neste sentido, pode levar em consideração o desempenho e o envolvimento, não só da organização, mas também dos grupos que interferem e contribuem para o seu sucesso e sobrevivência. O estudo colabora com a estratégia voltada para os stakeholders desde 1963 e a pesquisa sobre o tema continua contribuindo de uma forma empírica, em que se analisa a realidade das empresas para saber, de fato, quem pode afetar ou ser afetado diretamente pela efetivação dos objetivos de uma organização, conforme dito por Freeman (1984).

De acordo com Mitchell, Agle e Wood (1997), a abordagem dos stakeholders tem sido fundamental para a compreensão da empresa sobre seu papel e responsabilidade para com essas partes. Nesse contexto, os autores citam Jones (1980) exatamente para enfatizar a importância da declaração a respeito da responsabilidade social corporativa, onde diz que as empresas têm obrigações com os seus grupos constituídos na sociedade, que vão além dos contratos ou das leis escritas já estabelecidas.

Com a intenção de se ter um entendimento a respeito de algumas práticas administrativas aplicadas pelas empresas hoteleiras, esta pesquisa foi iniciada em 2008, com o objetivo de estudar a forma como as redes hoteleiras se relacionavam com o cliente e quais estratégias eram usadas para alcançar seus objetivos. Ao concluir esses estudos, que foram fundamentais para a compreensão e alinhamento do tema proposto, percebeu-se que seria enriquecedor para a pesquisa ampliar o estudo com a abordagem do relacionamento com os stakeholders, visto o envolvimento de outros grupos na condução do relacionamento com o cliente nas empresas hoteleiras. Após o aprofundamento do estudo e também com a ampliação da bibliográfica sobre a teoria dos stakeholders, levantou-se a seguinte questão de investigação: A gestão de stakeholders melhora a administração nas empresas hoteleiras? Propõe-se, como objetivo geral da pesquisa, compreender as relações existentes entre os 
stakeholders e as organizações hoteleiras. Como objetivos específicos procura-se observar se as organizações hoteleiras elaboram sua estratégia, de modo que contribua para o relacionamento entre os diferentes stakeholders, e compreender a relação existente entre o consumidor e os outros grupos ou indivíduos envolvidos no desempenho das organizações hoteleiras.

\section{METODOLOGIA}

Com a revisão da literatura, investigação preliminar, produção científica e conversa com especialistas sobre o tema proposto nesta pesquisa, chegou-se, primeiramente, à definição do problema e dos objetivos, e, devido à complexidade que envolve o estudo das ciências sociais, principalmente no que se refere à gestão nas organizações, a abordagem qualitativa com a metodologia voltada para o estudo de caso, seria a mais adequada para a investigação empírica, pois permite aos investigadores a compreensão dos acontecimentos da vida real e interpretá-los para a compreensão do fenômeno em questão. Yin (2010, p.24) colabora com este raciocínio quando diz que o estudo de caso "é usado em muitas situações, para contribuir ao nosso conhecimento dos fenômenos individuais, grupais, organizacionais, sociais, políticos e relacionados”, e sugere o método do estudo de casos múltiplos para possibilitar a análise comparativa.

Foram selecionadas três redes de hotéis, por reunirem características que viabilizariam a análise comparativa do estudo de acordo com o método sugerido por Yin (2010). A três organizações hoteleiras, Blue Tree Hotels, Bourbon Hotéis \& Resorts e Rede Estanplaza, atuam no mesmo setor, possuem unidades na cidade de São Paulo, com capital 100\% nacional e juntas, contam com um volume de negócios de 605 milhões de reais, possuem 51 empreendimentos entre nacionais e internacionais, 8.500 unidades habitacionais, empregam 6.345 pessoas e uma ocupação média entre 68 a $80 \%$. Esses dados foram obtidos por meio das três fontes de evidências escolhidas para o estudo: entrevistas, observações diretas e documentação. A primeira, entrevistas semiestruturadas, com tópicos de discussão aberta direcionadas aos principais dirigentes de cada organização, foi o principal instrumento de pesquisa. Para a seleção dos entrevistados, consideraram-se o grau de conhecimento e representatividade que eles exercem na organização escolhida para o estudo, os intuitos foram buscar uma visão mais ampla das estratégias praticadas pela empresa e assegurar maior veracidade das informações. Os três entrevistados selecionados foram: Chieko Aoki, Presidente da Blue Tree Hotels; Karen Yurie Tookuni, Gerente de Marketing da Rede Bourbon Hotéis \& Resorts e João Paulo de Andrade, Superintendente da Rede Estanplaza

Revista Ibero-Americana de Estratégia - RIAE, São Paulo, v. 10, n. 3, p. 94-125, set./dez. 2011. 
Hotels. As entrevistas foram realizadas no mês de maio de 2011, nos escritórios das respectivas redes hoteleiras.

Ao finalizar as entrevistas com os representantes das organizações acima citados, foi solicitada a possibilidade de se realizar uma segunda etapa de entrevistas que se aplicaria aos representantes dos grupos considerados mais relevantes pelo entrevistado. A finalidade dessa segunda etapa, foi evitar uma visão unilateral do estudo, ouvindo outros interlocutores que afetam ou são afetados pela realização dos objetivos da organização. Assim, foram indicados: Patrícia Garcia Marton, diretora de Operações da Rede Blue Tree; Maria Cristina Carvalho, diretora de Recursos Humanos da Rede Bourbon; Antônio Ivo Mendes de Albuquerque, diretor de Operações da Rede Estanplaza. Representado os intermediários foi indicado Francisco M. J. Leme da Silva, diretor da Jet Stream Turismo. Ao todo, foram realizadas sete entrevistas que somaram 5 horas de duração em áudio gravado que correspondem a 68 páginas de transcrições.

A segunda fonte de evidências foi a observação direta para identificar possíveis divergências com as entrevistas. A observação foi feita de forma espontânea em relação aos fatos que ocorrem no ambiente, inclusive durante a visita de campo, como nos dias das entrevistas. A terceira, documentação, para corroborar os dados das entrevistas e os das observações, foi feita por intermédio da análise de documentos das organizações, disponíveis online e solicitados e enviados por email aos pesquisadores. Para esta coleta de dados foram utilizadas as fontes secundárias, isto é, das organizações hoteleiras, em que foram analisados press releases, sites das organizações, textos publicitários, artigos de jornais, revisão bibliográfica e outros documentos pertinentes na investigação.

$\mathrm{Na}$ análise dos dados, para cada caso, as informações primeiramente foram colhidas e estudadas individualmente para depois serem organizadas, de forma a identificar os fatores determinantes que possibilitaram a comparação dos fatos. Em seguida, os dados foram agrupados combinando as similaridades e diferenças entre as três fontes de evidências. É por meio dessas três fontes que se forma a triangulação. Segundo Yin (2010, p.144) "Com a triangulação dos dados, os problemas potencias de validade do constructo também podem ser abordados, porque as múltiplas fontes de evidência proporcionam, essencialmente, várias avaliações do mesmo fenômeno". As três organizações foram comparadas em relação a gestão das ações e relacões desenvolvidas com os stakeholders. Isto foi feito a partir dos objetivos e da questão da pesquisa, estabelecendo a correspondência existente entre ambas para nortear o processo de análise dos dados. De acordo com Eisenhardt (1989), para uma interação dos dados no estudo de caso, deve-se avaliar a coerência destes em comparação com a teoria, para que se tenha um ajuste entre ambos, procurando 
aproveitar todas as perspectivas possíveis, como a sensibilidade do autor, o problema em estudo e a relevância da literatura.

\section{FUNDAMENTAÇÃO TEÓRICA}

Para um melhor desempenho nos negócios, o estudo dos stakeholders já faz parte da gestão das organizações desde a publicação do livro Strategic mangement: a stakeholder approach, por Freeman em 1984. O assunto já é citado há mais tempo, o primeiro documento foi de 1963 em um memorando da Stanford Research Institute (SRI), citado por Freeman e Reed em 1983. No entanto, foi com a publicação do livro de Freeman que esse assunto passou a ser incorporado na gestão e no pensamento dos gestores. De acordo com Mitchell, Agle e Wood (1997), a abordagem dos stakeholders tem sido fundamental para a compreensão da empresa sobre seu papel e responsabilidade para com as partes interessadas ou envolvidas no negócio. Essas partes podem ser as pessoas, os grupos, as comunidades, as organizações, as instituições, e as sociedades, que estão inseridas nas atividades da organização.

O conceito de stakeholder se tornou importante para compreender o relacionamento entre organização e sociedade, Carroll e Buchholtz (2003) dizem que para entender o conceito de stakeholder, deve se entender primeiro o significado de stake, que, segundo os autores, é o envolvimento de um indivíduo ou um grupo que participa de determinada decisão, seja ela por interesse, por direito ou por reivindicação. Pode-se verificar diferentes tipos de stakes, conforme Quadro 1. O envolvimento pode ser por um simples interesse de uma empresa ou por uma reivindicação legal de propriedade, em que, independentemente do tipo de participação, o que se pode priorizar é o direito a um tratamento justo que valorize o relacionamento com os envolvidos no negócio ou na decisão em questão, preservando a privacidade e a liberdade, sem obrigar (pressionar) ou discriminar. O direito também pode ser pensado como o direito moral, conforme os autores exemplificam com uma expressão de um empregado, "Eu tenho o direito de não ser demitido, pois eu trabalho nesta empresa há trinta anos", e, "Eu dei os melhores anos da minha vida para esta empresa”.

Revista Ibero-Americana de Estratégia - RIAE, São Paulo, v. 10, n. 3, p. 94-125, set./dez. 2011. 


\begin{tabular}{|c|c|c|}
\hline POR INTERESSE & POR DIREITO & POR PROPRIEDADE \\
\hline $\begin{array}{l}\text { Quando um indivíduo ou um } \\
\text { grupo for afetado por uma } \\
\text { decisão, este terá interesse } \\
\text { nesta decisão. } \\
\text { Exemplo: O fechamento da } \\
\text { fábrica irá afetar a } \\
\text { comunidade; } \\
\text { Este comercial de televisão } \\
\text { denigre a imagem da mulher, } \\
\text { e eu sou uma mulher. }\end{array}$ & $\begin{array}{l}\text { Direito Legal: Quando um indivíduo ou um } \\
\text { grupo possui um direito legal para ser tratado de } \\
\text { certa maneira ou de ter um direito particular } \\
\text { protegido. } \\
\text { Exemplo: Os empregados esperam privacidade } \\
\text { em processos legais; clientes e credores têm } \\
\text { certos direitos legais. } \\
\text { Direito Moral: Quando um indivíduo ou um } \\
\text { grupo acredita ter direito moral para ser tratado } \\
\text { de certa maneira ou de ter um direito particular } \\
\text { protegido. } \\
\text { Exemplo: Proteção, justiça e igualdade. }\end{array}$ & $\begin{array}{l}\text { Quando um indivíduo ou um } \\
\text { grupo tem um título legal de } \\
\text { um ativo ou de uma } \\
\text { propriedade. } \\
\text { Exemplo: "esta empresa é } \\
\text { minha, eu a fundei, eu sou o } \\
\text { dono", ou, "eu tenho mil ações } \\
\text { desta corporação". }\end{array}$ \\
\hline
\end{tabular}

Quadro 1- Tipos de stakes.

Fonte: Carroll e Buchholtz (2003, p. 70). Adaptado e traduzido pela autora.

Os stakeholders primários, clientes, empregados, fornecedores, acionistas e comunidade, segundo Freeman, Harisson e Wicks (2007), são os mais importantes para a empresa, pois sem eles as organizações não sobreviveriam. É interessante ressaltar a equiparação dos acionistas com os outros stakeholders, como empregados, fornecedores e clientes, visto que, os acionistas não têm a segurança dos resultados, dependem do desempenho e do resultado no final do processo, enquanto os outros já garantem sua participação em acordos por meio de contratos pré-definidos. Os grupos primários são caracterizados pela complexidade das relações, pois possuem interesses, objetivos, expectativas e responsabilidades diferenciadas em relação aos objetivos da empresa. Os administradores, segundo os autores, precisam entender os valores e os objetivos deste primeiro grupo e priorizar o relacionamento para um melhor desempenho e alcance dos melhores resultados. O papel da comunidade pode ser enfatizado neste primeiro grupo priorizando o diálogo, alguns conflitos existentes entre organizações e comunidade decorrem justamente pelo fato das empresas ignorarem a comunidade como um parceiro importante.

Os stakeholders secundários, também podem influenciar e afetar o desempenho das operações da empresa. É possível citar, como exemplo, as ações governamentais que influenciam a entrega de produtos e serviços, afetando diretamente o relacionamento dos interessados primários, podendo assim desestabilizar o fluxo de informações entre clientes, empregados e acionistas. $\mathrm{Na}$ concepção de Carroll e Buchholtz (2003), os stakeholders são classificados na mesma categoria que os de Freeman, Harisson e Wicks (2007), eles, os primeiros autores, os nomeiam como primários e secundários social stakeholders, e, acrescentam mais uma categoria - não-social; os primários não-

Revista Ibero-Americana de Estratégia - RIAE, São Paulo, v. 10, n. 3, p. 94-125, set./dez. 2011. 
social stakeholders (Primary nonsocial stakeholders) - que são: ambiente natural, gerações futuras e espécie não-humana - e os secundários não-social stakeholders (Secondary nonsocial stakeholders) - que são: grupos que exercem pressão ambiental e organizações que defendem os animais. Nessa perspectiva de raciocínio eles concordam com a necessidade da classificação dos stakeholders de acordo com a influência dos grupos, conforme as categorias apresentadas, mas alertam, por exemplo, quanto ao poder e influência da mídia e de outros grupos de interesse especial que podem transformar o status de um stakeholder e inverter sua posição na organização.

Quanto à definição da prioridade dos stakeholders, Freeman, Harisson e Wicks (2007) dizem que existem várias maneiras tanto de definir quanto de descrever as partes interessadas em um negócio. Cabe a cada organização mapear os seus stakeholders, para que se construa um relacionamento com seus grupos ou indivíduos, enfatizando as ações orientadas de acordo com os objetivos traçados. Mitchell, Agle e Wood (1997), dizem que as empresas podem escolher duas direções para administrarem as partes interessadas, primeiro, em um sistema centralizado, em que elas podem identificar todas as partes pensando em sua sobrevivência por meio de controle de danos econômicos a fim de aproveitar oportunidades e construir alianças para reforçar sua influência, principalmente sobre políticas públicas; segundo, por um sistema mais aberto, em que elas possam administrar os stakeholders, visando a participação de todos, dentro de um equilíbrio entre a priorização de reivindicações e de interesses dentro do sistema social da empresa de uma forma justa e compensadora. Em ambos os casos, é necessário conhecer os reais e potenciais influenciadores, com o objetivo de diferenciar os grupos que têm obrigação legal, moral ou uma reivindicação presumida sobre a empresa e daqueles que têm capacidade de influenciar o comportamento da empresa, na direção, processo ou nos resultados.

Para Freeman, Harisson e Wicks (2007), a relevância de cada grupo depende de variáveis ligadas ao negócio de cada empresa, é por meio do histórico armazenado de cada stakeholder que as informações adquiridas permitem uma análise global do envolvimento e do tipo de relacionamento que se pode estabelecer com cada um deles. Eles sugerem uma matriz como exemplo, na qual se estabelecem quatro questões relevantes para análise dos stakeholders: segurança do produto, integridade dos relatórios financeiros, serviços de novos produtos e retorno financeiro, e para cada grupo se constitui uma pontuação de acordo com o grau de importância estabelecido entre as questões relevantes e o grupo de interesse. Esta matriz permite aos gestores a identificação dos pontos relevantes e a posição em que se encontra o stakeholder no processo de desempenho empresarial, o que permite avaliá-los, atendê-los e formular estratégias voltadas para o interesse dos grupos como um todo.

Revista Ibero-Americana de Estratégia - RIAE, São Paulo, v. 10, n. 3, p. 94-125, set./dez. 2011. 
Stakeholders: Estratégia Organizacional e Relacionamento. Estudo de Casos Múltiplos do Setor Hoteleiro

Pode-se levar em consideração as reações e comportamentos dos grupos para sua administração e viabilização de criação de valor. Ainda segundo Freeman, Harisson e Wicks (2007) é importante que a empresa compreenda quando que um grupo pode contribuir ou prejudicar os negócios, e estar preparada para reagir, tanto para evitar as reações negativas, quanto para fortalecer as positivas.

A identificação e a relevância dos stakeholders são amplamente citadas nos estudos e percebe-se concordância de que todos os grupos devem ser envolvidos no processo de decisão da empresa, mas, cabe a gerência, por meio do relacionamento, identificar quais são as partes mais importantes para a tomada de determinada decisão. Bourne (2009) enfatiza que o relacionamento dentro das organizações é uma ação fundamental para identificação e priorização dos grupos que podem contribuir com seu sucesso ou fracasso.

A relação entre empresa e sociedade está intrínseca com as questões éticas e sociais, Carroll e Buchholtz (2003) dizem que as mudanças que há algum tempo vêm ocorrendo nos negócios, em que o cliente assume o foco do negócio e o produto está atrelado às suas necessidades e exigências, vão além de um bom produto, pois, os clientes esperam responsabilidades econômicas, sociais, ambientais e éticas em relação a sociedade. A sociedade é composta de diferentes grupos e subgrupos, ela é formada por pessoas, mulheres, minorias, ambientalistas, juventude e por sistemas políticos, religiosos, econômicos, culturais, de direitos e costumes. Para as organizações, esses múltiplos grupos são seus stakeholders, grupos ou indivíduos com quem estabelecem relações sociais. Na representação abaixo (Figura 1), o negócio está posicionado no centro do círculo e ligado diretamente com seus stakeholders primários, governo, empregados, clientes, acionistas e comunidade, que mantém ligação com outras esferas ou grupos formando uma interconexão. Nesse contexto, o relacionamento com estes grupos se torna mais complexo, os pontos de interface não são simples, requerendo grande envolvimento dos gestores para sua compreensão e realização.

Revista Ibero-Americana de Estratégia - RIAE, São Paulo, v. 10, n. 3, p. 94-125, set./dez. 2011. 
Figura 1- Negócios e o relacionamento com stakeholders.

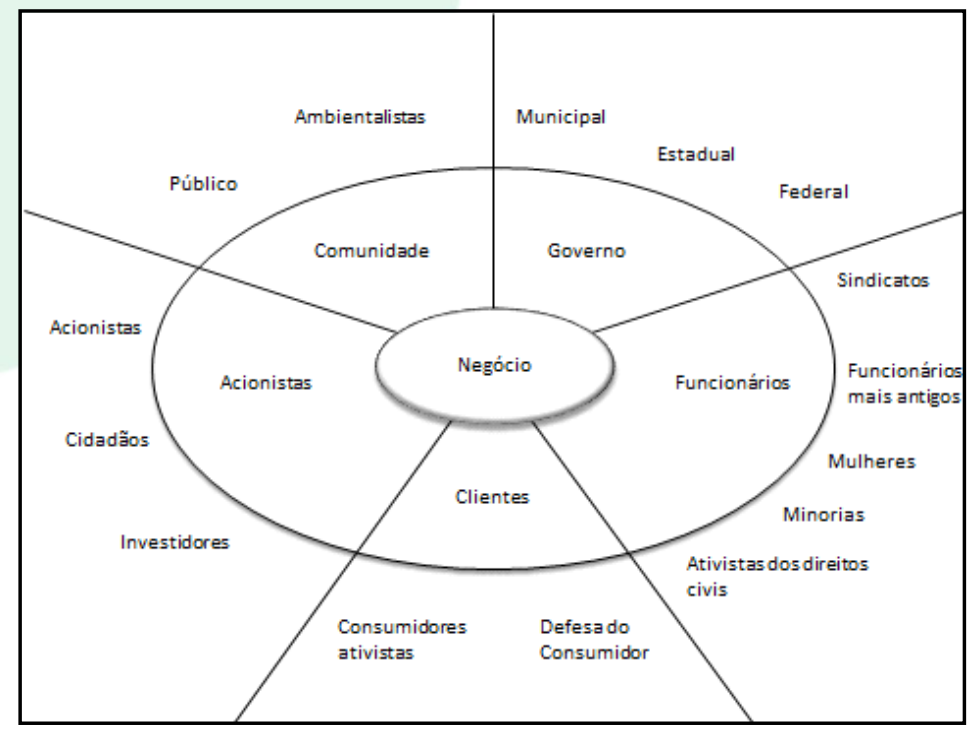

Fonte: Carroll e Buchholtz (2003, p. 9). Traduzido pela autora.

O envolvimento das organizações com seus grupos de interesses requer conhecimento para que se tenha uma relação que seja construtiva e produtiva para os envolvidos no negócio. Compreender as expectativas da sociedade em relação à conduta social e ética das organizações se tornou essencial, a pressão exercida por grupos que podem estar ligados, direta ou indiretamente, ao negócio já é uma realidade. As pressões vão além da conduta social e ética das organizações, a sociedade espera também que as empresas tenham atitude em relação à responsabilidade social. Freeman, Harisson e Wicks (2007) acreditam que se as empresas se relacionarem em conjunto com seus stakeholders e raciocinarem sobre os negócios, de uma forma responsável e respeitosa, elas criam assim, valor para os stakeholders. Os autores afirmam, "In fact, we might even define "CSR" as "corporate stakeholders responsibility" to symbolize that thinking about stakeholders is just thinking about the business and vice versa" (p. 99). Se a empresa tiver uma atitude voltada para criação de valor para os stakeholders, ela não necessita pensar em termos de responsabilidade social, essa atitude já está intrínseca na realização do negócio.

A literatura sobre estratégia organizacional é consistente, diversificada e de interesse de muitos pesquisadores, Mintzberg (1993) diz que havia uma distância entre a prática e a teoria. Os responsáveis por desenvolver e criar os projetos das organizações não tinham acesso a literatura por serem escritas com base em pesquisa empírica, com uma linguagem acadêmica direcionada, principalmente, a outros pesquisadores, que, mesmo com a tentativa de verificar estudos reais, não conseguiam interagir com os gestores das organizações. Com essa percepção, o autor propõe um

Revista Ibero-Americana de Estratégia - RIAE, São Paulo, v. 10, n. 3, p. 94-125, set./dez. 2011. 
estudo capaz de sintetizar a literatura em uma visão integrada com a estruturação organizacional. Esse estudo sugere que a eficácia da estratégia nas organizações se baseie em atender tanto a missão da empresa quanto as necessidades dos envolvidos no negócio, ou seja, os proprietários, as agências governamentais, os sindicatos dos trabalhadores e grupos que exercem pressão nas decisões, ou seja, os seus stakeholders. Costa, Boaventura e Silva (2010) também citam a importância da formulação de estratégias voltadas para o envolvimento dos stakeholders, em uma pesquisa realizada em órgãos públicos municipais de turismo do estado de São Paulo, os autores dizem que,

[...] considera-se importante aumentar a consciência em relação ao progresso da estratégia no turismo e prover uma base inicial para a formulação de um pensamento, bem como a realização de um debate contínuo neste importante tema, em níveis local, nacional e internacional. Cabe ainda mencionar a relevância que o setor público assume no processo de formulação de estratégias para destinos turísticos, por meio da sua capacidade de envolver os diversos stakeholders e de nortear as ações a serem tomadas para a organização da atividade [...]. (Costa, Boaventura e Silva, 2010, p. 111)

Freeman, Harisson e Wicks (2007), reforçam este pensamento e dizem que no século XXI, com a globalização do mercado, já não é mais adequado o modelo gerencial em que os acionistas centralizam sua importância e decisões. A abordagem deve captar o melhor dos dois lados, de fora para dentro e de dentro para fora, reconhecer a centralidade de vários stakeholders e destacar a importância de valores e ética no núcleo do negócio. A estratégia empresarial com uma abordagem do negócio é voltada para os princípios de valor e ética, visto que os dois não devem ser separados. Os autores citam quatro principais componentes que estão inter-relacionados, são eles: objetivos e valores, stakeholders e princípios, contexto social e responsabilidade, liderança ética; que podem direcionar os objetivos, de uma forma clara, em que se priorizem os valores para se construir a base do relacionamento e para entender o motivo e interesse dos stakeholders em fazer negócios com a organização. As estratégias corporativas voltadas para liderança ética envolvendo os stakeholders e questões sociais podem ser analisadas de várias formas, representando o conjunto de respostas e ações específicas para cada momento e circunstâncias pelo qual a empresa está vivenciando. O cerne das estratégias se concentra no envolvimento dos stakeholders dentro de um compromisso em que os valores e as questões sociais prevaleçam e garantam a elevação dos benefícios da empresa para com os grupos envolvidos na realização dos negócios.

Allison e Kaye (2005) dizem que quando as organizações declaram seus valores de uma forma clara e objetiva para seus stakeholders, elas facilitam a articulação desses valores e proporcionam aos grupos a oportunidade de considerar as semelhanças existentes entre eles. É a partir desta identificação que se pode estabelecer a confiança e o compromisso dos stakeholders

Revista Ibero-Americana de Estratégia - RIAE, São Paulo, v. 10, n. 3, p. 94-125, set./dez. 2011. 
para com a organização e fortalecer o relacionamento. Carroll e Buchholtz (2003) colaboram com esse pensamento e argumentam que as responsabilidades éticas são atividades e práticas aceitas ou refutadas pela sociedade. Mesmo não sendo leis escritas, elas estão inseridas na mente das pessoas e formam um conjunto de normas, padrões e expectativas. A sociedade espera que esse conjunto de normas se estabeleça como princípios de justiça e são esperados como atitude das empresas em relação às pessoas que estão envolvidas no negócio, seja de uma forma direta ou indireta. Freeman, Harisson e Wicks (2007, p. 156) dizem, "We have a real opportunity to be the generation that makes capitalism better. The choice is ours". Os autores acreditam que é pela gestão dos stakeholders que se pode mudar a visão de negócio e deixar um modelo mais justo para a geração futura. A criação de valor para as partes interessadas ficaria no centro, a visão seria global e os envolvidos no negócio teriam uma participação nas decisões da empresa com mais equidade. Os produtos e serviços seriam criados de acordo com o interesse de todos os envolvidos, possibilitando uma melhor condição de vida à humanidade, sem deixar de criar valor financeiro para os acionistas.

\section{ANÁLISE DOS RESULTADOS}

Para entender melhor a relação da organização com seus stakeholders foram inicialmente identificados os stakeholders com maior potencial de cooperação junto à organização. A identificação foi feita conforme sugerido por Chevalier e Buckles (2008) citado por Reed et al (2009), onde recomendam a elaboração de uma lista das prováveis partes interessadas, para, posteriormente, serem colocadas em um esquema de "arco-íris" considerando três graus de influência, baixo, moderado e alto.

No início das entrevistas com os dirigentes das organizações, foi apresentado um mapa com quatorze grupos que, supostamente, afetavam ou eram afetados pelo desenvolvimento dos objetivos das organizações, acrescentado a opção para adicionar outros stakeholders, por meio da pesquisa documental. A partir desse mapa, onze grupos foram classificados em moderado e alto grau. Assim, foi possível diagnosticar os grupos nos quais as organizações reconhecem sua influência na condução do negócio, considerando o momento atual de cada organização. Com a identificação dos stakeholders foi possível explorar as relações com eles estabelecidas, que foram analisadas separadamente para, posteriormente, serem comparadas Foram abordadas as ações de colaboração e de aproximação, sua relação com as questões éticas e sociais e a transparência nas informações e a condução do relacionamento.

Revista Ibero-Americana de Estratégia - RIAE, São Paulo, v. 10, n. 3, p. 94-125, set./dez. 2011. 


\section{CASO 1 - BLUE TREE HOTELS}

\section{GESTÃO DAS RELAÇÕES COM OS STAKEHOLDERS}

Nas entrevistas com os representantes da rede ficou claro que a base do relacionamento é a confiança. Nesse contexto, todas as ações, de aproximação e participação, são orientadas estrategicamente pela empresa em parceria com os funcionários e outros stakeholders envolvidos nas decisões da empresa (Tabela 1). Percebem-se poucas ações declaradas pelas entrevistadas em relação à comunidade, citadas como as quatro mais importantes para a organização.

Tabela 1- Ações e gestão das relações com stakeholders na rede Blue Tree.

\begin{tabular}{|c|l|}
\hline AÇÕES E GESTÃO DAS RELAÇÕES COM STAKEHOLDERS \\
\hline Comunidade & \multicolumn{1}{|c|}{ Incentivo a educação e a qualificação para uma melhor qualidade de vida. } \\
\hline Concorrentes & $\begin{array}{l}\text { Acompanhamento das ações. } \\
\text { Comitês junto a associações do setor hoteleiro. }\end{array}$ \\
\hline Consumidores & $\begin{array}{l}\text { Evento institucional denominado a Festa das Mulheres em que se reúne consumidores e } \\
\text { intermediários, tais como as secretárias e executivas das agências e operadoras. } \\
\text { Ações voltadas para fidelização e relacionamento com o objetivo de encantar esse } \\
\text { consumidor. } \\
\text { Ações voltadas para administração de conflito em que se busca manter todas as equipes que } \\
\text { lidam diretamente com o consumidor alinhadas por um objetivo comum. }\end{array}$ \\
\hline Funcionários & $\begin{array}{l}\text { Planual, integração e envolvimento dos funcionários para elaboração do planejamento } \\
\text { estratégico anual. } \\
\text { Convenções com as equipes realizadas mensalmente para discutir as melhorias e práticas de } \\
\text { excelência em serviços para elaboração do planejamento. } \\
\text { Projeto "Elogiaram Você" em que o funcionário recebe um elogio do consumidor pelos } \\
\text { serviços a ele prestado. Os elogios são deixados nos guest comments e em outros canais de } \\
\text { percepção junto ao consumidor usados pela organização Por meio desse projeto, os } \\
\text { funcionários que se destacaram são premiados e participam do projeto "talento do ano". } \\
\text { Talento do mês, funcionário que se destacou durante o mês perante colegas e consumidores } \\
\text { são premiados. } \\
\text { Treinamento e incentivo educacional proporcionado a todos os funcionários. } \\
\text { Participação na pesquisa da revista Exame, Melhor empresa para se Trabalhar, usada para } \\
\text { melhorar o relacionamento a a satisfação junto aos funcionários. } \\
\text { Projeto Celebrar para valorizar o momento de vida do funcionário, se ele tem algo para ser } \\
\text { comemorado, como aniversário de casamento, o filho que passa no vestibular e outras } \\
\text { celebrações, isso será compartilhado com os colegas, é uma forma de valorizar a vida de cada } \\
\text { um deles. }\end{array}$ \\
\hline
\end{tabular}

Revista Ibero-Americana de Estratégia - RIAE, São Paulo, v. 10, n. 3, p. 94-125, set./dez. 2011. 


\begin{tabular}{|c|l|}
\hline \multirow{2}{*}{ Intermediário } & $\begin{array}{l}\text { Eventos de confraternização. } \\
\text { Visitas constantes, ações voltadas mais para o setor comercial. } \\
\text { Blitz na cidade para oferecer mimos, presentes, divulgar um novo produto. } \\
\text { Evento institucional a "Festa das Mulheres" que envolve outros grupos. } \\
\text { A principal ação é estar presente e ser lembrado, dar um mimo, fazer festa. }\end{array}$ \\
\hline Investidores & $\begin{array}{l}\text { Jantar oferecido na casa de Aoki como encerramento e agradecimento da parceria realizada } \\
\text { durante aquele ano. } \\
\text { Açontatos individualizados. } \\
\text { Assembleias com objetivo de incentivar na participação e compromisso com a elaboração das } \\
\text { estratégias. } \\
\text { Eventos esporádicos, visitas constantes. }\end{array}$ \\
\hline
\end{tabular}

Fonte: Elaboração das autoras com base nas entrevistas (2011).

A empresa reforça as relações com seus stakeholders pela missão, crenças e valores, que são sempre divulgadas e discutidas com os envolvidos no negócio. Na entrevista, Aoki diz, "na Blue Tree nós valorizamos muito a missão, a cultura e os valores. Isso tudo tem que estar casado, disso nós não abrimos mão. Nós temos reunião de lideranças toda segunda feira e começamos falando da missão e dos valores, sempre.” Allison e Kaye (2005) reforçam esse pensamento e dizem que para a construção do compromisso com os stakeholders, as organizações precisam explicitar, atualizar e debater seus valores essenciais com todos os interessados no negócio.

A organização acredita que pela doação pode influenciar os valores das pessoas e, nesse sentido, alguns stakeholders são envolvidos no processo de doação, como os clientes e funcionários, fornecedores e intermediários para que se tenha uma integração maior tanto com a empresa quanto com a sociedade como um todo. As ações sociais estão ligadas diretamente a satisfação dos funcionários e, consequentemente, estabelecem reconhecimento vindo da comunidade em que eles estão inseridos. A organização está apoiada em metas estratégicas direcionadas para ações socioambientais para todos os hotéis, justamente para que se tenha coerência com os princípios da organização. A relação entre empresa e sociedade está intrínseca com as questões éticas e sociais. Para Carroll e Buchholtz (2003), as empresas sofrem constantemente pressões decorridas da opinião pública, empunhada pela mídia, que interfere diretamente em suas ações, provocando nova abordagem e mudança de conduta que levam em consideração as questões éticas e sociais.

Revista Ibero-Americana de Estratégia - RIAE, São Paulo, v. 10, n. 3, p. 94-125, set./dez. 2011. 


\section{CASO 2 - BOURBON HOTÉIS \& RESORTS}

\section{GESTÃO DAS RELAÇÕES COM OS STAKEHOLDERS}

A organização procura adequar suas estratégias, de forma que os principais stakeholders tenham uma participação ativa nas decisões. Com ferramentas de comunicação adequadas, a empresa mantém o diálogo aberto com os grupos de maior interesse e influência para a organização. A gestão das relações da rede é voltada para a construção da marca junto à sociedade, priorizando a missão da organização que é garantir a plena satisfação de clientes, funcionários e investidores com lucratividade. Tookuni diz que é pela eficiência nessa gestão que se pode garantir o crescimento da rede, levando em consideração sua sustentabilidade e a real satisfação dos envolvidos no negócio. Os mecanismos utilizados na gestão das relações com seus principais stakeholders foram elencados pelas entrevistadas, conforme demonstrado na Tabela 2.

Tabela 2- Ações e gestão das relações com os stakeholders na rede Bourbon.

\begin{tabular}{|c|c|}
\hline Comunidade & $\begin{array}{l}\text { Responsabilidades sociais e iniciativas junto às instituições. } \\
\text { Construção de escolas e bibliotecas em algumas cidades. } \\
\text { Programa de treinamento, de capacitação, de profissionalização. } \\
\text { Iniciativas internas de conscientização e preservação do meio ambiente, começando com o } \\
\text { funcionário e depois passando para a comunidade. } \\
\text { Apoio à projetos direcionados para melhoria da comunidade. }\end{array}$ \\
\hline Concorrentes & $\begin{array}{l}\text { Acompanhamento das ações. } \\
\text { Comitês junto a associações do setor hoteleiro. }\end{array}$ \\
\hline Consumidores & $\begin{array}{l}\text { O atendimento é a principal interação com esse grupo. } \\
\text { Metas juntos aos funcionários para atendimento e satisfação do consumidor. } \\
\text { Fidelização. } \\
\text { Pesquisa de satisfação. } \\
\text { Ferramentas website, newsletters. } \\
\text { Programa interno para resolver possíveis reclamações ou oportunidades de melhorias. }\end{array}$ \\
\hline Funcionários & $\begin{array}{l}\text { Treinamento técnico e comportamental, capacitação profissional. } \\
\text { Convênio com instituições de ensino para capacitação em que a organização paga } 20 \% \text { do } \\
\text { curso. } \\
\text { Escola Bourbon de hotelaria. } \\
\text { Programa de desenvolvimento de liderança (PDL). } \\
\text { Encontros entre áreas para troca de experiência. } \\
\text { Encontros de gestores. } \\
\text { Convenção de vendas. } \\
\text { Bourbon News mensal. } \\
\text { Programa de imersão a cada seis meses. } \\
\text { Concurso de sugestões de melhoria dos serviços. } \\
\text { Programas de integração. }\end{array}$ \\
\hline
\end{tabular}

Revista Ibero-Americana de Estratégia - RIAE, São Paulo, v. 10, n. 3, p. 94-125, set./dez. 2011. 


\begin{tabular}{|c|l|}
\hline \multicolumn{1}{|c|}{ Governo } & A gestão das relações, considerando que a organização como um todo fica com o trade. \\
\hline Intermediário & Ações específicas de vendas. \\
\hline Investidores & $\begin{array}{l}\text { Encontros realizados pelo diretor de desenvolvimento para entender as necessidades, os } \\
\text { objetivos e as expectativas. } \\
\text { Reuniões extraordinárias. } \\
\text { Assembleia para apresentação da proposta de ano versus ano. } \\
\text { Ferramentas de comunicação impressa e eletrônica. } \\
\text { Cada hotel tem um programa específico de relações com os investidores. }\end{array}$ \\
\hline Mídia & $\begin{array}{l}\text { Agência específica para mídias sociais. } \\
\text { Mecanismo para promover a transparência nas informações. } \\
\text { Plano de mídia. } \\
\text { Assessoria de impressa e ferramentas de comunicação direta com consumidores. } \\
\text { Campanhas internas e ferramentas de endomarketing. } \\
\text { Ferramentas de comunicação desenvolvida para cada player. }\end{array}$ \\
\hline
\end{tabular}

Fonte: Elaboração das autoras com base nas entrevistas (2011).

Um fato a ser observado é a importância de que a rede apresenta em relação à mídia, percebe-se isso tanto pelas entrevistas quanto pelas outras fontes de evidências, observação e documentação que a organização tem um investimento diferenciado na gestão de comunicação. A rede está investindo atualmente em mídias sociais, pois acredita que esse será o diferencial para a organização. Para reforçar esse pensamento, é importante citar a pesquisa feita pela Deloitte (2010, p.6), em que é feita a seguinte observação, "para que exista uma melhor utilização das mídias sociais, as empresas precisam estabelecer porta-vozes para sua marca, que se preocupem em conversar com o mercado e extrair dele valor para seus negócios. As empresas precisam enfim, "humanizar-se" por meio de mídias sociais". O cliente se sente mais a vontade no ambiente virtual e está mais propício a executar um maior número de atividades online, onde ele procura por novas amizades e também está aberto a passar pela experiência de compras. Nas redes sociais, o consumidor troca informações com pessoas desconhecidas, mas nas quais confia, justamente pela identificação estabelecida entre eles. E é o intercâmbio de informações sobre produtos e fornecedores que influenciaria nas decisões de compra. Essa identidade que se constrói nas redes sociais é responsável pelo sucesso das interações entre empresas e consumidores, isto considerando as mídias sociais como um pilar estratégico.

Revista Ibero-Americana de Estratégia - RIAE, São Paulo, v. 10, n. 3, p. 94-125, set./dez. 2011. 


\section{CASO 3 - REDE ESTANPLAZA}

\section{GESTÃO DAS RELAÇÕES COM OS STAKEHOLDERS}

A organização percebe seus grupos de maior influência como determinantes para o seu sucesso ou insucesso e ressalta que o diferencial está nas relações de aproximação com cada um deles. A administração é voltada, principalmente, para os investidores, consumidores, intermediários e funcionários.

O modelo de gestão da empresa é desenhado para a participação dos stakeholders e, como exemplo, Albuquerque (2011) diz, "a nossa vida, os nossos produtos ou a vida dos nossos colaboradores que se refere a prontuários é aferida constantemente através dos canais de escuta que a empresa tem". A partir dessa participação, via projetos, escutas e aferição de indicadores, a organização tem possibilidade de entender melhor esses grupos por meio de um histórico consistente que permite desenvolver estratégias voltadas para o interesse dos envolvidos no negócio. Freeman, Harisson e Wicks (2007) contribuem com esse raciocínio quando argumentam que a relevância de cada grupo depende de variáveis ligadas ao negócio de cada empresa, é por meio do histórico armazenado de cada stakeholder que as informações adquiridas permitem uma análise global do envolvimento e do tipo de relacionamento que se pode estabelecer com cada um deles.

A organização traça suas estratégias de acordo com os dados coletados dos envolvidos no negócio e, assim, modifica seus produtos, em razão da influência dos grupos em busca dos melhores resultados. Algumas dessas ações voltadas para a gestão que proporcionam o acompanhamento e controle das relações com seu stakeholders mais expressivos, foram citadas nas entrevistas e apresentadas na Tabela 3 .

Tabela 3 - Ações e gestão das relações com os stakeholders na rede Estanplaza.

\begin{tabular}{|c|l|}
\hline Concorrentes & $\begin{array}{l}\text { Relacionamento pessoal forte. } \\
\text { Participação junto ao FOHB em reuniões frequentes. } \\
\text { Controle diário em relação à diária média dos concorrentes, market share. }\end{array}$ \\
\hline Consumidores & $\begin{array}{l}\text { Envolvimento em ações sociais por meio do preenchimento do guest comment, em que para } \\
\text { cada guest preenchido se doa de R } \$ 2,00 \text { a } \mathrm{R} \$ 2,50 \text { para uma determinada instituição } \\
\text { filantrópica. } \\
\text { Fidelização. } \\
\text { Pesquisa de satisfação. } \\
\text { Metas de satisfação junto ao funcionário. }\end{array}$ \\
\hline
\end{tabular}

Revista Ibero-Americana de Estratégia - RIAE, São Paulo, v. 10, n. 3, p. 94-125, set./dez. 2011. 


\begin{tabular}{|c|c|}
\hline Fornecedores & $\begin{array}{l}\text { Ficha de avaliação com todo o histórico. } \\
\text { Criação de valor, respeito e flexibilidade na negociação em prol da longevidade. }\end{array}$ \\
\hline Funcionários & $\begin{array}{l}\text { Os funcionários são priorizados na organização e participam ativamente no desenvolvimento } \\
\text { das estratégias. Nesse contexto, a contribuição, tanto das propostas quanto da prática, é feita } \\
\text { em conjunto com os envolvidos, por meio de projetos distribuídos em diferentes níveis de } \\
\text { comitês. } \\
\text { Ações internas de retenção de talentos. } \\
\text { Jornalzinho Estanplaza com } 800 \text { exemplares, direcionados para funcionários e familiares. } \\
\text { Prêmio pelas } 10 \text { melhores atitudes reconhecidas pelos consumidores, via guest comment. } \\
\text { Avaliação mensal por indicadores. } \\
\text { Participação no resultado mensal do empreendimento. } \\
\text { Atitudes premiadas com incentivos em educação. } \\
\text { Projeto líderes educadores, em que por meio de uma avaliação por méritos aferidos, os } \\
\text { funcionários são classificados por um grupo de pessoas e, dependendo dos resultados, ele } \\
\text { passa a ser um líder educador. }\end{array}$ \\
\hline Intermediários & $\begin{array}{l}\text { Relacionamento de parceria e respeito. } \\
\text { Festas de confraternização a cada } 3 \text { meses nos empreendimentos, com entrega de brindes } \\
\text { para os agentes de viagens. } \\
\text { Mecanismos de avaliação de resultados por indicadores, keep eyes. } \\
\text { Carta acordo para garantia de tarifa e disponibilidade. }\end{array}$ \\
\hline Investidores & $\begin{array}{l}\text { Reunião semestral para discutir propostas de decisões relativas ao empreendimento. } \\
\text { Assembleias para aprovação das propostas. } \\
\text { Relacionamento próximo e promoção da interação e nos projetos. }\end{array}$ \\
\hline
\end{tabular}

Fonte: Elaboração das autoras com base nas entrevistas (2011).

A gestão das relações voltadas para os funcionários foi a mais citada pelos entrevistados. $\mathrm{O}$ grupo é priorizado, de acordo com Andrade, porque o diferencial está no fator humano, que representa $90 \%$ da atividade da organização. O sucesso do negócio depende da proximidade e interligação com os grupos e os funcionários pelo comprometimento e é o principal pilar para promover a interação de acordo a missão da organização.

\subsection{ANÁLISE COMPARATIVA}

Para cada caso, as informações foram colhidas e estudadas em profundidade para depois serem organizadas, de forma a identificar os fatores determinantes que possibilitaram a comparação dos fatos. Após a análise de cada uma das três organizações separadamente, os dados foram agrupados para compará-los entre si. De acordo com Eisenhardt (1989), para uma interação dos dados no estudo de caso, deve-se avaliar a coerência destes em comparação com a teoria, para que se tenha um ajuste entre ambos, procurando aproveitar todas as perspectivas possíveis, como a sensibilidade do autor, o problema em estudo e a relevância da literatura.

Revista Ibero-Americana de Estratégia - RIAE, São Paulo, v. 10, n. 3, p. 94-125, set./dez. 2011. 
Stakeholders: Estratégia Organizacional e Relacionamento. Estudo de Casos Múltiplos do Setor

Hoteleiro

\section{PRINCIPAIS STAKEHOLDERS E SUA RELEVÂNCIA}

Tabela 4 - Quatro grupos considerados mais importantes pelas organizações.

\begin{tabular}{|c|c|c|c|}
\hline STAKEHOLDERS & BLUE TREE & BOURBON & ESTANPLAZA \\
\hline Comunidade & $\mathrm{x}$ & $\mathrm{x}$ & $\mathrm{x}$ \\
\hline Consumidores & $\mathrm{x}$ & $\mathrm{x}$ & $\mathrm{x}$ \\
\hline Fornecedores & & $\mathrm{x}$ & $\mathrm{x}$ \\
\hline Funcionários & $\mathrm{x}$ & $\mathrm{x}$ & $\mathrm{x}$ \\
\hline Intermediários & & $\mathrm{x}$ & \\
\hline Investidores & & & \\
\hline
\end{tabular}

Fonte: Elaboração das autoras com base nas entrevistas (2011).

No início das entrevistas, foi solicitado aos entrevistados que eles citassem quatro grupos considerados mais importantes para o desenvolvimento dos objetivos da organização. As respostas estão relacionadas na Tabela 4, em que se pode verificar que os consumidores e os funcionários foram citados pelas três organizações. A observação a ser feita é com a rede Estanplaza que se diferenciou das demais, elegendo os fornecedores e os intermediários enquanto as redes Blue Tree e Bourbon elegeram comunidade e investidores. Um dos fatores que podem contribuir com essa diferença seria a localização da rede, enquanto as duas redes estão em várias regiões do Brasil e no caso Blue Tree também internacional e Bourbon já em fase final de internacionalização, com um empreendimento previsto para ser lançado em setembro/2011, em Assunção, a rede Estanplaza tem todos os seus empreendimentos localizados na cidade de São Paulo e Andrade justifica o baixo relacionamento com a comunidade, justamente pelo fato de os empreendimentos estarem localizados em uma cidade cosmopolita e em áreas comerciais.

Quanto aos investidores, pode se verificar outro fator, conforme dito nas entrevistas, a Estanplaza administra empreendimentos construídos pela empresa do mesmo grupo, Concivil, que detém uma percentagem da propriedade de cada imóvel e vende o restante. Desse modo, a Estanplaza tem sempre uma participação nos empreendimentos por ela administrados, enquanto isso

Revista Ibero-Americana de Estratégia - RIAE, São Paulo, v. 10, n. 3, p. 94-125, set./dez. 2011. 
Rosemeire Rodrigues Junqueira \& Elizabeth Kyoko Wada

não acontece com as outras redes. Neste sentido, pode-se justificar a importância dada aos investidores.

Quanto à relevância dos stakeholders, de acordo com um quadro de grupos pré-selecionados apresentado aos entrevistados, pode-se perceber a importância que cada organização tem com relação aos stakeholders (Tabela 5).

Tabela 5 - Stakeholders considerados mais relevantes pelas organizações.

\begin{tabular}{|c|c|c|c|}
\hline STAKEHOLDERS & BLUE TREE & BOURBON & ESTANPLAZA \\
\hline Acionistas & $\mathrm{x}$ & $\mathrm{x}$ & $\mathrm{x}$ \\
\hline Comunidade & $\mathrm{x}$ & $\mathrm{x}$ & \\
\hline Concorrentes & & & $\mathrm{x}$ \\
\hline Consumidores & $\mathrm{x}$ & $\mathrm{x}$ & $\mathrm{x}$ \\
\hline Def. Consumidor & & & \\
\hline Fornecedores & $\mathrm{x}$ & & $\mathrm{x}$ \\
\hline Funcionários & $\mathrm{x}$ & $\mathrm{x}$ & $\mathrm{x}$ \\
\hline Governo & $\mathrm{x}$ & & \\
\hline Inst. Financeiras & & & \\
\hline Inst. Sociais & & & $\mathrm{x}$ \\
\hline Intermediário & $\mathrm{x}$ & $\mathrm{x}$ & $\mathrm{x}$ \\
\hline Investidores & $\mathrm{x}$ & & \\
\hline Mídia & & $\mathrm{x}$ & \\
\hline Sindicatos & & & \\
\hline
\end{tabular}

Fonte: Elaboração das autoras com base nas entrevistas (2011).

Revista Ibero-Americana de Estratégia - RIAE, São Paulo, v. 10, n. 3, p. 94-125, set./dez. 2011. 
É interessante observar que entre 14 grupos apresentados na Tabela 5, quatro grupos foram citados como relevantes pelas três organizações: acionistas, consumidores, funcionários e intermediários. A diferença que se pode destacar é a comunidade não priorizada pelo Estanplaza. Freeman, Harisson e Wicks (2007) falam que o papel da comunidade pode ser enfatizado no grupo primário, priorizando o diálogo, pois alguns conflitos existentes entre organizações e comunidade, decorrem justamente pelo fato de as empresas ignorarem a comunidade como um parceiro importante. Esses autores ainda chamam a atenção para a influência dos ambientalistas no tocante às decisões da empresa com a comunidade e com alguns segmentos de clientes. Os concorrentes também são mencionados só pela rede Estanplaza e pelos fornecedores que não foram mencionados pela rede Blue Tree. Enquanto em relação ao governo e aos investidores, a rede Blue Tree foi a única a mencionar, justamente pelos seus empreendimentos fora do país, onde o relacionamento com esses grupos poderia adquirir características diferenciadas.

Quanto à mídia, vale a pena ressaltar a posição da rede Bourbon, que foi a única a mencioná-la como prioritária para o desenvolvimento do negócio. A rede está com investimentos direcionados para mídias sociais, conforme dito nas entrevistas, não sendo ainda possível fazer uma análise dos resultados, mas a rede intui que ela poderá ser o diferencial no futuro.

\section{Relacionamento com os stakeholders}

As organizações desenvolvem várias ferramentas e ações para se relacionar com seus principais stakeholders. Percebem-se diferenças na gestão de acordo com a importância que cada organização aplica aos grupos considerados por elas prioritários. Para facilitar a interpretação e comparação entre as redes, os grupos foram separados conforme as tabelas comparativas.

Na gestão das relações com a comunidade (Tabela 6), a Rede Bourbon apresenta o maior investimento nas ações com o grupo, sendo algumas voltadas para responsabilidades sociais e filantrópicas. A Rede Blue Tree apresenta ações voltadas para educação. A Rede Estanplaza não cita ações voltadas para a comunidade quando solicitado na entrevista, mas percebem-se essas ações quando se fala das instituições sociais. A rede desenvolve várias ações de ajuda a uma instituição. Carroll e Buchholtz (2003) consideram que as responsabilidades filantrópicas se distinguem das responsabilidades éticas porque não são esperadas no sentido moral ou ético. A comunidade tem o desejo e espera que as empresas invistam parte dos seus recursos financeiros em programas humanitários, e em melhoria de qualidade de vida para seus funcionários, mas se a empresa não oferecer esses serviços, isso não significa falta de ética.

Revista Ibero-Americana de Estratégia - RIAE, São Paulo, v. 10, n. 3, p. 94-125, set./dez. 2011. 
Rosemeire Rodrigues Junqueira \& Elizabeth Kyoko Wada

Tabela 6 - Gestão das relações com a comunidade.

\begin{tabular}{|c|c|c|c|}
\hline AÇÕES & BLUE TREE & BOURBON & ESTANPLAZA \\
\hline Incentivo à educação & $\mathrm{x}$ & $\mathrm{x}$ & \\
\hline Responsabilidade social & & $\mathrm{x}$ & \\
\hline $\begin{array}{c}\text { Iniciativas de conscientização e } \\
\text { preservação do meio ambiente }\end{array}$ & & $\mathrm{x}$ & \\
\hline Apoio a projetos de melhoria & & & \\
\hline
\end{tabular}

Fonte: Elaboração das autoras com base nas entrevistas (2011).

Com os concorrentes, a gestão das relações apresenta uma equidade entre as redes (Tabela 7) e que os mecanismos são direcionados mais para vigilância (benchmarking) do que como parceria e colaboração.

Apenas a Rede Estanplaza se refere à troca de experiências promovida pelo relacionamento pessoal. Andrade (2011) faz a seguinte afirmação, [...] Primeiro nós temos um relacionamento pessoal muito forte, porque parte dos gerentes de hotel se formou comigo e nós acabamos mantendo isso $[\ldots]$.

Tabela 7 - Gestão das relações com os concorrentes.

\begin{tabular}{|c|c|c|c|}
\hline AÇÕES & BLUE TREE & BOURBON & ESTANPLAZA \\
\hline Acompanhamento das ações & $\mathrm{x}$ & $\mathrm{x}$ & $\mathrm{x}$ \\
\hline $\begin{array}{c}\text { Comitês junto a associações do } \\
\text { setor }\end{array}$ & $\mathrm{x}$ & $\mathrm{x}$ & $\mathrm{x}$ \\
\hline Relacionamento pessoal & & & $\mathrm{x}$ \\
\hline
\end{tabular}

Fonte: Elaboração das autoras com base nas entrevistas (2011).

Revista Ibero-Americana de Estratégia - RIAE, São Paulo, v. 10, n. 3, p. 94-125, set./dez. 2011. 
Stakeholders: Estratégia Organizacional e Relacionamento. Estudo de Casos Múltiplos do Setor

Hoteleiro

$\mathrm{Na}$ gestão das relações com os consumidores, um quadro interessante se apresenta, as três redes mencionam as mesmas ações de relacionamento com esse grupo (Tabela 8). Foi priorizado um grupo por todos os entrevistados e quando se fez a pesquisa documental percebeu-se que o foco é direcionado para os consumidores. As ações empregadas com os outros stakeholders, muitas vezes, são justificadas por proporcionarem melhor atendimento e retorno para o grupo como um todo. Swift, (2001) articula que é a estratégia da organização que vai determinar quais processos são necessários para a criação de valor para os clientes (consumidores), as pessoas envolvidas podem conseguir melhorias contínuas necessárias para manter as empresas à frente de seus concorrentes, atingindo assim, um dos objetivos principais da estratégia das organizações. Atualmente, uma das melhores fontes de vantagem competitiva é a excelência e a melhoria contínua do relacionamento com o cliente.

Tabela 8 - Gestão das relações com os consumidores.

\begin{tabular}{|c|c|c|c|}
\hline AÇÕES & BLUE TREE & BOURBON & ESTANPLAZA \\
\hline Eventos de confraternização & $\mathrm{x}$ & $\mathrm{x}$ & $\mathrm{x}$ \\
\hline Fidelização & $\mathrm{x}$ & $\mathrm{x}$ & $\mathrm{x}$ \\
\hline Administração de conflito & $\mathrm{x}$ & $\mathrm{x}$ & $\mathrm{x}$ \\
\hline Metas de satisfação & $\mathrm{x}$ & $\mathrm{x}$ & $\mathrm{x}$ \\
\hline Pesquisas de satisfação & $\mathrm{x}$ & $\mathrm{x}$ & $\mathrm{x}$ \\
\hline
\end{tabular}

Fonte: Elaboração das autoras com base nas entrevistas (2011).

Com os funcionários (Tabela 9) são desenvolvidas diferentes ações na gestão das relações. Trata-se de um grupo que apresenta, ao mesmo tempo, um potencial de colaboração e de ameaça pelas três organizações pesquisadas. O treinamento e a participação no planejamento estratégico são enfatizados pelos entrevistados. Percebe-se que apesar das iniciativas, as redes ainda não conseguiram criar mecanismos suficientes ou eficientes para diminuir a rotatividade do grupo. 
Como é um stakeholder considerado muito importante para o sucesso das organizações, talvez fosse necessário repensar a gestão dessa relação.

Tabela 9 - Gestão das relações com os funcionários.

\begin{tabular}{|c|c|c|c|}
\hline AÇÕES & BLUE TREE & BOURBON & ESTANPLAZA \\
\hline $\begin{array}{c}\text { Integração e envolvimento na } \\
\text { elaboração de planejamento }\end{array}$ & $\mathrm{x}$ & $\mathrm{x}$ & $\mathrm{x}$ \\
\hline Convenções & $\mathrm{x}$ & $\mathrm{x}$ & $\mathrm{x}$ \\
\hline Projetos de avaliação e premiação & $\mathrm{x}$ & $\mathrm{x}$ & $\mathrm{x}$ \\
\hline Talento do mês & $\mathrm{x}$ & $\mathrm{x}$ & $\mathrm{x}$ \\
\hline Treinamento e incentivo \\
educacional
\end{tabular}

Fonte: Elaboração das autoras com base nas entrevistas (2011).

Os intermediários (Tabela 10) são considerados grupos influenciadores e que interferem diretamente no negócio das empresas, são chamados como parceiros por estarem ligados diretamente aos resultados da empresa. Segundo Leme (2011), o relacionamento estabelecido com as organizações hoteleiras é sempre comercial, enquanto deveria envolver outras áreas, outros diretores, isso, por um relacionamento mais estreito e mais eficaz.

Revista Ibero-Americana de Estratégia - RIAE, São Paulo, v. 10, n. 3, p. 94-125, set./dez. 2011. 
Stakeholders: Estratégia Organizacional e Relacionamento. Estudo de Casos Múltiplos do Setor

Hoteleiro

Aoki (2011) diz na entrevista que a gestão do relacionamento com o intermediário pode ser estabelecido pelo "ganha, ganha", o que é bom para um lado tem que ser bom também para o outro, ou seja, a qualidade e o valor final devem ser os mesmos. Aoki (2011) completa, “[...] porque senão o cliente final vai ser prejudicado. Nem todos são assim. Temos problemas? Temos problemas, mas nós temos que caminhar para isso, que trabalhar para isso. Temos que mostrar que essa forma é a forma melhor". Com esse entendimento, percebe-se que o relacionamento pode ser melhorado e que pela aproximação possa se chegar a um consenso.

Tabela 10 - Gestão das relações com os intermediários.

\begin{tabular}{|c|c|c|c|}
\hline AÇÕES & BLUE TREE & BOURBON & ESTANPLAZA \\
\hline Eventos de confraternização & $\mathrm{x}$ & & $\mathrm{x}$ \\
\hline $\begin{array}{c}\text { Visitas constantes pela equipe } \\
\text { comercial }\end{array}$ & $\mathrm{x}$ & $\mathrm{x}$ & $\mathrm{x}$ \\
\hline $\begin{array}{c}\text { Ações específicas de vendas } \\
\text { Avaliação de resultados por } \\
\text { indicadores }\end{array}$ & $\mathrm{x}$ & & $\mathrm{x}$ \\
\hline Carta acordo & & & $\mathrm{x}$ \\
\hline
\end{tabular}

Fonte: Elaboração das autoras com base nas entrevistas (2011).

No agrupamento das ações voltadas para as relações com os investidores (Tabela 11) podese observar uma semelhança entre os mecanismos adotados pelas redes para se relacionar com esse stakeholder. $\mathrm{O}$ grupo foi comentado na Tabela 5 e discutido sobre as diferenças de priorização entre as redes.

Revista Ibero-Americana de Estratégia - RIAE, São Paulo, v. 10, n. 3, p. 94-125, set./dez. 2011. 
Rosemeire Rodrigues Junqueira \& Elizabeth Kyoko Wada

Tabela 11 - Gestão das relações com os investidores.

\begin{tabular}{|c|c|c|c|}
\hline AÇÕES & BLUE TREE & BOURBON & ESTANPLAZA \\
\hline Evento de confraternização & $\mathrm{x}$ & $\mathrm{x}$ & $\mathrm{x}$ \\
\hline Transparência & $\mathrm{x}$ & $\mathrm{x}$ & $\mathrm{x}$ \\
\hline Divulgação de resultados & $\mathrm{x}$ & $\mathrm{x}$ & $\mathrm{x}$ \\
\hline Contatos individualizados & $\mathrm{x}$ & $\mathrm{x}$ & $\mathrm{x}$ \\
\hline Assembleias & $\mathrm{x}$ & $\mathrm{x}$ & $\mathrm{x}$ \\
\hline Participação na elaboração de & $\mathrm{x}$ & $\mathrm{x}$ & \\
\hline estratégias & & & \\
\hline Reuniões extraordinárias & & & \\
\hline Avaliação de resultados & & & \\
\hline
\end{tabular}

Fonte: Elaboração das autoras com base nas entrevistas (2011).

A Rede Bourbon apresenta um número maior de ações em relação à mídia (Tabela 12). Nesse aspecto, a rede se destaca em algumas iniciativas em mídias sociais, como uma agência específica para esse tipo de mídia. Em uma investigação sobre a influência da Internet no setor turístico, Buhalis e Kaldis (2008) concluem que houve uma revolução nas condições de mercado das empresas do setor. O desenvolvimento da Internet, ainda em fase de amadurecimento, mantém o foco na reestruturação da gestão e comercialização de produtos usando tecnologias que proporcionam a interação com seus clientes, de forma dinâmica, confiável e rápida. A interação pode ser feita de acordo com o conceito de redes sociais e comunidades virtuais.

Quanto à posição da Rede Estanplaza, Andrade (2011) diz na entrevista que não acredita na divulgação de informações pagas e que sua estratégia da organização tem como base o marketing de relacionamento pessoal. A aproximação e a comunicação com todos os stakeholders são feitas por meio de um relacionamento direto e por ferramentas internas que viabilizam o feeback de cada um

Revista Ibero-Americana de Estratégia - RIAE, São Paulo, v. 10, n. 3, p. 94-125, set./dez. 2011. 
deles. Em relação a conflitos que possam vir a acontecer, a organização tem um plano de gerenciamento de risco em que se prevêem respostas imediatas por meio de sua assessoria de imprensa e de executivos que lidam diretamente com os grupos. Freeman, Harisson e Wicks (2007) dizem que as empresas podem levar em consideração as reações e o comportamento dos grupos para sua administração e para viabilização de criação de valor. É importante que a empresa compreenda quando que um grupo pode contribuir ou prejudicar os negócios e estar preparada para reagir, tanto para evitar as reações negativas, quanto para fortalecer as positivas.

Tabela 12 - Gestão das relações com a mídia.

\begin{tabular}{|c|c|c|c|}
\hline AÇÕES & BLUE TREE & BOURBON & ESTANPLAZA \\
\hline $\begin{array}{c}\text { Agência específica para mídias } \\
\text { sociais }\end{array}$ & & $\mathrm{x}$ & \\
\hline Transparência nas informações & & $\mathrm{x}$ & \\
\hline Plano de mídia & $\mathrm{x}$ & $\mathrm{x}$ & $\mathrm{x}$ \\
\hline Assessoria de imprensa & $\mathrm{x}$ & $\mathrm{x}$ & $\mathrm{x}$ \\
\hline Endomarkentig & $\mathrm{x}$ & $\mathrm{x}$ & \\
\hline Comunicação direcionada & & & \\
\hline
\end{tabular}

Fonte: Elaboração das autoras com base nas entrevistas (2011).

\section{CONSIDERAÇÕES FINAIS}

Por meio da investigação literária, de pesquisa documental, de observações e de entrevistas com representantes de diferentes grupos que afetam ou são afetados pelo desenvolvimento dos objetivos das organizações, foi possível desenvolver argumentos que contribuíram para melhor compreender a gestão com os stakeholders em organizações hoteleiras e para cumprir os objetivos propostos e responder a questão de investigação.

Buscou-se explorar a gestão das relações com os principais grupos apontados pelas organizações. É interessante ressaltar que as organizações elegeram os consumidores, funcionários,

Revista Ibero-Americana de Estratégia - RIAE, São Paulo, v. 10, n. 3, p. 94-125, set./dez. 2011. 
comunidade, investidores como seus principais grupos, sendo considerados grupos primários, e apenas uma rede que não elegeu a comunidade como tal e elegeu em seu lugar os fornecedores. De acordo com Freeman, Harisson e Wicks (2007), os grupos primários são caracterizados pela complexidade das relações, pois possuem interesses, objetivos, expectativas e responsabilidades diferenciadas em relação aos objetivos da empresa. Os administradores, segundo os autores, precisam entender os valores e os objetivos desse primeiro grupo e priorizar o relacionamento para um melhor desempenho e alcance dos melhores resultados.

A gestão das relações com os principais grupos foi amplamente analisada e foi percebido que as organizações podem estar em processo de amadurecimento quando considerada a distribuição e criação de valor. As organizações procuram identificar os pontos relevantes de seus principais stakeholders por meio de ferramentas de avaliações desenvolvidas para cada um deles. É com base na análise dos resultados, que as empresas desenvolvem suas estratégias de acordo com o interesse de cada grupo, de modo a alinhar os objetivos com o todo. Com funcionários e consumidores é possível perceber maior envolvimento de valores intrínsecos, tais como confiança, transparência e solidariedade, que ultrapassam as regras e formalidades empresariais, com os outros grupos percebe-se que existe um esforço de aproximação para superar as diferenças e passar para uma gestão mais humanitária e igualitária, mas que ainda não está consistente, pois é compreendida com base em regras rígidas contratuais e, em alguns casos, sem flexibilidade.

As organizações pesquisadas assumem a priorização pelos consumidores e agenciam os outros grupos com o objetivo de proporcionar a esse stakeholder a melhor satisfação. É pelo intermédio dessa articulação em prol do consumidor que se institui a troca entre organizações e seus stakeholders, confiando na premissa de que consumidor satisfeito assegura a rentabilidade do negócio e esta por sua vez é revertida para os outros grupos envolvidos. Carroll e Buchholtz (2003) citam as mudanças que há algum tempo vêm ocorrendo nos negócios, em que o cliente assume o foco do negócio e o produto está atrelado às necessidades e exigências do cliente. As exigências vão além de um bom produto, eles esperam responsabilidades econômicas, sociais, ambientais e éticas em relação a sociedade. A sociedade é composta de diferentes grupos e subgrupos, ela é formada por pessoas, mulheres, minorias, ambientalistas, juventude e por sistemas políticos, religiosos, econômicos, culturais, de direitos e costumes. Para as organizações, esses múltiplos grupos são seus stakeholders, grupos ou indivíduos com quem estabelecem relações sociais.

Para responder a problemática da pesquisa, "A gestão de stakeholders melhora a administração nas empresas hoteleiras?”, entende-se que sim, que já não é mais viável administrar sem ter a participação direta dos grupos que influenciam e são influenciados pelo desenvolvimento

Revista Ibero-Americana de Estratégia - RIAE, São Paulo, v. 10, n. 3, p. 94-125, set./dez. 2011. 
dos objetivos da organização. A gestão voltada para a transparência, ética, valores e, principalmente, pelo respeito mútuo se torna mais colaborativa e pode aumentar a sustentabilidade, a longevidade das organizações. Freeman, Harisson e Wicks (2007) dizem que no século XXI, com a globalização do mercado, já não é mais adequado o modelo gerencial em que os acionistas centralizam sua importância e decisões. A abordagem deve captar o melhor dos dois lados, de fora para dentro e de dentro para fora, reconhecer a centralidade de vários stakeholders e destacar a importância de valores e da ética no núcleo do negócio.

As organizações pesquisadas argumentam sobre a união e integração com os envolvidos no negócio, como consumidor, funcionários e acionistas, pensando na importância da qualidade de vida como um todo. É com a melhoria da qualidade de vida dos envolvidos que se pode alcançar um melhor desempenho organizacional. Para tanto, é necessário que os instrumentos de gestão façam parte sistemática da elaboração e desenvolvimento da estratégia para não correr o risco do esforço ser mal aproveitado em relação às ações dispensadas em uma administração mais justa.

\section{REFERÊNCIAS}

Allison, M., Kaye, J.(2005) Strategic planning for nonprofit organizations: a practical guide and workbook. (2 ed.) Hoboken, New Jersey: Wiley \& Sons, Inc.

Bourne, L. (2009) Stakeholder relationship management: a maturity model for organisational implementation. Burlington: Ashgate Publishing Company.

Blue Tree Hotels. (2011) Recuperado em 14 fev.2011, de: http://www.bluetree.com.br/.

Bourbon Hotel \& Resorts. (2011) Recuperado em 14 fev.2011, de: http://www.bourbon.com.br/.

Buhalis, D., Kaldis, K. (2008) eEnabled internet distribution for small and medium sized hotels: the case of hospitality SMEs in Athens. Tourism Recreation Research, 33 (1).

Carroll, A.B., Buchholtz, A.B. (2003) Business and society: ethics and stakeholder management. (5 Ed.). Ohio: Thomson South - Western.

Costa, B. K.; Boaventura, J.M.G.; Silva, L.M.T. (2010) Formulação de estratégias no turismo: um estudo em órgãos municipais do Estado de São Paulo. Turismo em Análise, 21, 110-129.

Revista Ibero-Americana de Estratégia - RIAE, São Paulo, v. 10, n. 3, p. 94-125, set./dez. 2011. 
Deloitte Touche Tohmatsu. (2010) Mídias sociais nas empresas: o relacionamento online com o mercado. Recuperado em 21 nov.2010, de: http://www.deloitte.com/view/pt_BR/br/perspectivas/estudosepesquisas.

Eisenhardt, K. M. (Oct., 1989) Building theories from case study research. Academy of Management Review, 14(4), 532-550. Recuperado em 10 março 2011, de: http://links.jstor.org/sici?sici=0363-

7425\%28198910\%2914\%3A4\%3C532\%3ABTFCSR\%3E2.0.CO\%3B2-R.

Freeman, R. E., Harisson, J. S., Wicks, A.C.(2007) Managing for stakeholders: survival, reputation, and success. Yale University Press. New Haven and London.

Freeman, R.E.(1984) Strategic management: a stakeholder approach. Pitman Publishing. Boston.

Mintzberg, H.(1993) Structure in fives - desingning, effective, organizations. Englewood Cliffs, New Hersey. Prentice Hall, Inc. A Simon \& Schuster Company.

Mitchell, R., Agle, D.J., Wood, BR. (1997) Toward a theory of stakeholder identification and salience: defining the principle of who and what really counts. Academy of Management Review, 22(4), 853-886. Recuperado em 25 nov.2010, de: https://wiki.brown.edu/confluence/download/attachments/33494/Mitchell+Stakeholder+Identific ation+1997.pdf.

Reed, M.S.,Graves, A., Dandy, N., Posthumus, H., Hubacek, K.,Morris, J., Prell, C., Quinn, C. H., Stringer, L. C. (Feb. 2009) Who's in and Why? A typology of stakeholder analysis methods for natural resource managemente. Journal of Environmental Management, 90, 1933-1949. http://dx.doi.org/10.1016/j.jenvman.2009.01.001

Rede Estanplaza. Recuperado em 14 fev.2011, de: http://www.estanplaza.com.br/grupo-estanplaza/.

Swift, R.(2001) CRM - Customer relationship management - O revolucionário marketing de relacionamento com o cliente. (11 ed.). Rio de Janeiro: Elsevier Editora Ltda.

Yin, R.K.(2010) Estudo de caso: planejamento e métodos. (4 ed.). Porto Alegre: Bookman.

Revista Ibero-Americana de Estratégia - RIAE, São Paulo, v. 10, n. 3, p. 94-125, set./dez. 2011. 
Stakeholders: Estratégia Organizacional e Relacionamento. Estudo de Casos Múltiplos do Setor Hoteleiro

Recebido: 27/09/2011

Aprovado: 08/11/2011

Revista Ibero-Americana de Estratégia - RIAE, São Paulo, v. 10, n. 3, p. 94-125, set./dez. 2011. 